\title{
Accidental Emission of Ammonia from Cold Storage and Ice Factory in Kolkata and its Remedial Action
}

\author{
Gargi Bhattercharjee, S. Bhattacharya, R.K. Gangopadhyay and S.K. Das
}

\begin{abstract}
This paper describes the incidents of accidental release of ammonia in three different industrial establishments. Human and maintenance error are the main cause behind the all incidents. This paper identified the errors, suggested some general recommendations, some preventive measure to be taken for such accident and also for the emergency situation.
\end{abstract}

Keywords--- Ammonia, Maintenance Error, Accident

Emission, Human Error,

\section{INTRODUCTION}

A MMONIA is used as refrigerant, has a low boiling point $\left(-28^{\circ} \mathrm{F}\right.$ psig), an ozone depletion potential (ODP) is zero when released to atmosphere, and a high latent heat of vaporization (9 times greater than R-12). Ammonia in the atmosphere does not directly contribute to global warming. Ammonia refrigeration systems cost $10-20 \%$ less to install than systems using CFC, HCFC etc. Thermodynamically, ammonia is $3-10 \%$ more efficient than other refrigerants; as a result ammonia systems use less electricity. The cost of ammonia itself is significantly less than other industrial refrigerants and less ammonia is also generally required to do the job as compared to other industrial refrigerants. All of this adds up to lower operating costs for food processors and cold storage facility operators, and that means lower grocery bills for the average household. The worldwide production of ammonia is estimated to be well over 100 million metric tons. Over $80 \%$ used for agriculture purpose like, direct injection into soil as a fertilizer in cold countries, production of urea (used as fertilizer and in feed), pre-harvest cotton defoliant, anti-fungal agent on certain fruits and only less than $2 \%$ used for refrigeration (closed systems).

Ammonia is a chemically reactive gas, much lighter than air (vapour density 0.59 of that of air). Cold vapour (e.g. from leaks) may however be denser than air. Pure ammonia vapors is not flammable at concentrations of less than $16 \%$, it may be

Gargi Bhattacharjee, Chemical Engineering, University of Calcutta, Kolkata.

S.Bhattacharya, Chemical Engineering, University of Calcutta, Kolkata.

R.K. Gangopadhyay, Chemical Engineering, University of Calcutta, Kolkata.

S.K. Das, Chemical Engineering, University of Calcutta, Kolkata. Email:drsudipkdas@vsnl.net inflammable and explosion hazard at concentrations between $16-25 \%$.

Ammonia is corrosive and exposure will result in a chemical-type burn. It is highly hygroscopic; and readily transforms the moist areas of the body such as eyes, nose, throat, and moist skin areas. Release of ammonia has potentially for harmful effects on workers and the public. Although there have been incidents of exposure to harmful concentrations of ammonia in the world there have been few fatal accidents. Inhaling ammonia causes irritation in the upper respiratory system. Exposure $50 \mathrm{ppm}$ or more results in immediate irritation to the nose and throat, but tolerance to ammonia develop with repeated exposure. Acute exposure to higher levels of $500 \mathrm{ppm}$ is very dangerous for life. Accidental exposures of high concentrations of ammonia gas have resulted in nasopharyngeal and tracheal burns, airway obstruction and respiratory distress, and bronchiolar and alveolar edema. Ammonia vapor readily dissolves in the moisture present on the skin, eyes, oropharynx and lungs forming ammonium hydroxide which dissociates to yield hydroxyl ions. Chronic occupational exposure to low levels of ammonia in air $(<25 \mathrm{ppm})$ had little effect on pulmonary function but decrease in lung function parameters [7]. Ammonia is also slightly irritating to human eyes in a brief exposure at concentrations of $100 \mathrm{ppm}$. Acute symptoms are inflamed eyes, swelling abrasions, and of the eyelids, hyperemic conjunctiva, blurred vision, possible transient blindness, corneal sustained corneal damage. Exposure to an air concentration of $250 \mathrm{ppm}$ is bearable for most persons for 30-60 minutes. The acute ammonia exposure resulted spasms of muscles and also affects the nervous system [8].

Henderson and Haggard [1] tabulated the physiological responses of ammonia and are presented in Table 1. The National Institute for Occupational Safety and Health (NIOSH) recommended time-weighted average (TWA) for anhydrous ammonia is $25 \mathrm{ppm}(18 \mathrm{mg} / \mathrm{m} 3)$ and the short-term exposure limit (STEL) is the same [3]

The paper describes three industrial accidents occurred in and around Kolkata in the cold storage and ice factory. These incidents have affected the working and outside environment and health injuries to the adjacent people. The probable causes of the accidents, the remedial measure and how to tackle the emergency situation have been discussed. 
Table 1: Acute Toxicity: Physiological Response

\begin{tabular}{|c|c|}
\hline Response & Concentration (ppm) \\
\hline Immediate dangerous to life and health & 500 \\
\hline Minimal irritation & 5 \\
\hline Moderate irritation & $9-50$ \\
\hline Definite irritation & $125-137$ \\
\hline $\begin{array}{c}\text { Cyclic hyperpnea/ upper respiratory } \\
\text { irritation, persistent }\end{array}$ & $500(30 \mathrm{~min})$ \\
\hline Immediate irritation & 700 \\
\hline $\begin{array}{c}\text { Dyspnea, convulsive coughing, chest } \\
\text { pain, pulmonary edema may be fatal }\end{array}$ & 1,500 to 10,000 \\
\hline
\end{tabular}

\section{BASIC PROCESS DESCRIPTION FOR COLD STORAGE}

A simple ammonia refrigerant system theoretically needs 4 components, evaporator; compressor; condenser; and reducing valve and is presented in Fig. 1. In practice other components such as oil separator, intercooler, liquid receiver, surge drum and liquid pumps are often found.

The useful refrigeration is produced at the evaporator where the liquid ammonia at low pressure, low temperature, takes in heat and vaporizes. This vapour is removed by the compressor, which in compressing it, raises the temperature from below to above ambient temperature. The hot compressed gas gives up the heat by condensing to a liquid in the condenser. The high-pressure liquid then passes through the pressure-reducing valve to the evaporator. At the valve the liquid is cooled as some vapour flashes off. The remaining liquid is available for use in the evaporator. In practice other components like oil separator removes suspended oil carried over from the compressor and either returns it to the system or holds it for draining in some way. There may be a multi-stage compressor with an intercooler. This is cooled by bleeding high-pressure liquid into the low-pressure side. Downstream of the condenser is generally a liquid receiver. Downstream of the reducing valve is often found to be a surge drum that acts as a reservoir of cold liquid and evens out demand on the compressor and condenser. The liquid ammonia is drawn from the surge drum by a pump. Oil drains may be found on surge drums, liquid receivers, and elsewhere on large plants. There is also likely to be an automatic control system on all but the oldest and smallest plants.

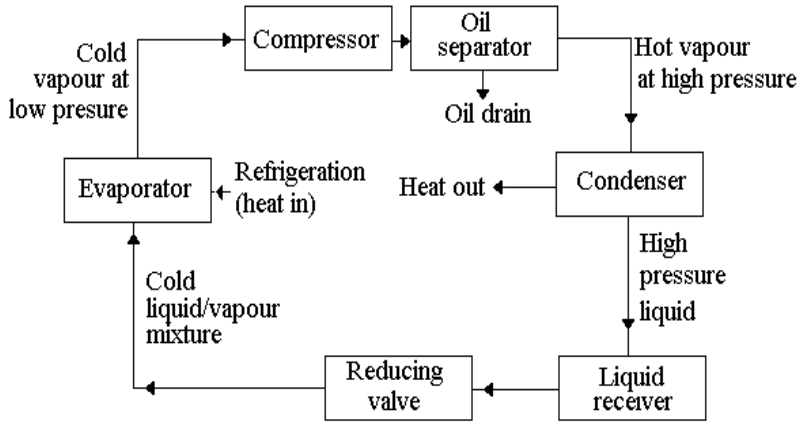

Figure 1: Simple Flow Diagram for Ammonia Refrigeration System

\section{A. Incident-1}

- Rupture of Manifold during Transfer of Ammonia from Cylinder to Receiver

The charging of ammonia from the ammonia cylinder of $65 \mathrm{~kg}$ capacity into the liquid line connected to the suction side of the ammonia compressor. The connection was made by a flexible rubber hose (maximum pressure withstand $\approx 12$ $\mathrm{kg} / \mathrm{cm} 2$ ) coupled by fixing nozzle. Fig. 2 illustrates the detailed connection of the cylinder to the main line. The charging line was provided with a $1 / 4$ inch globe valve, V3, and a short piece of iron pipe. The $1 / 2$ inch angle valve, V1, of the storage tank and $\mathrm{V} 2$, reducing valve connected into the system as shown in figure 2. In the transfer process, the operator opened valve V1 not the valve V2. So the line was directly connected with the storage tank with a pressure $15-18 \mathrm{~kg} / \mathrm{cm} 2$. As soon as the operator opened the V3 valve he observed that ammonia was coming out profusely from the junction point of the short iron pipe and the rubber hose where a crack of 2 inch length was developed. Two fire brigade engines arrived in the spot and sprayed large amount of water to dissolved ammonia. The operator used the self-containing breathing apparatus from the fire brigade and closed the valve V1 and V3. The leakage of ammonia lasted about $30 \mathrm{~min}$. Nine people from adjacent areas were affected and all of them were sent to local hospital for first aid treatment.

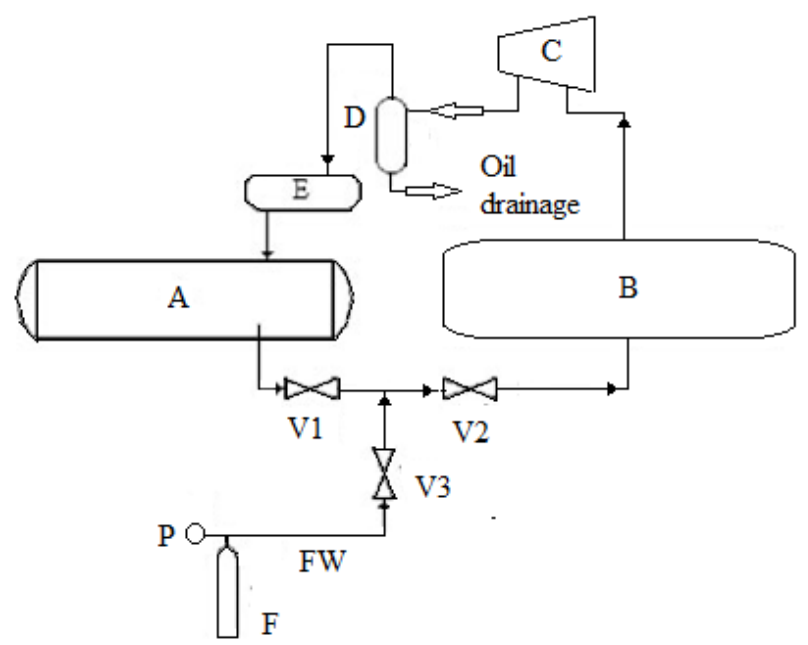

Figure 2: Schematic Representation of the Refrigeration System A: Ammonia Storage Tank, B: Evaporator, C: Compressor, D: Oil Separator, E: Condenser, F: Ammonia Cylinder, P: Pressure Gauge, V1: 1/2 Inch Angle Valve, V2: Reducing Valve, V3: 1/4 Inch Globe Valves, FW: Flexible Rubber Hose

\section{B. Incident-2}

- Oil separator drain line threads failure

In a refrigeration unit drain line of the oil separator detached from the oil separator $(2 \mathrm{ft}$ in diameter and $6 \mathrm{ft}$ in height) body all on a sudden causing massive leakage of ammonia inside and outside the factory. Fig. 3 shows the schematic diagram of the oil drum. Two workers with selfcontaining breathing apparatus entered into the accident spot and isolate the oil tank. The plant management started the 
water sprinkler arrangement in the plant to control the situation. Entire plant was shut down after about 10 minutes of the incident occurs. The situation was controlled partially with the help of water sprinkler arrangement. Thirty workers were affected and all were transferred to local hospital for treatment and released after first-aid.

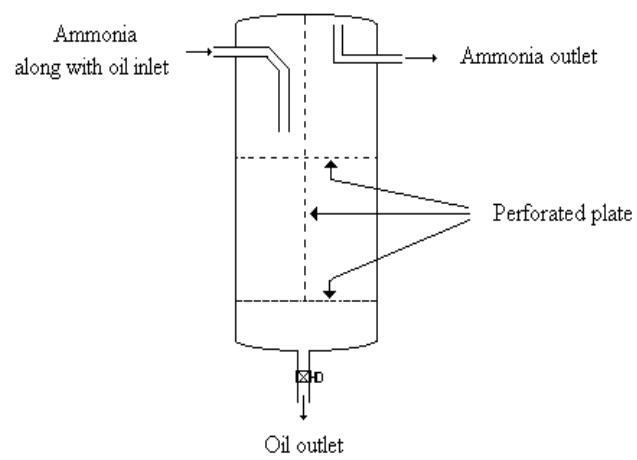

Figure 3: Schematic Diagram of the Oil Separator Drum

C. Incident -3

- $\quad$ Leakage of ammonia from cold storage [4]

At least 70 people fell ill in Dum Dum's Nagerbazar area, West Bengal, India on 23rd Jan. 2011 Sunday evening after inhaling poisonous ammonia gas which leaked out of a cold storage in the neighbourhood. There was widespread panic, leading to the deployment of BSF's disaster-response team. The entire area was cordoned off and traffic diverted for several hours. Around 3,000 people were evacuated before the leak could be plugged.

Six fire tenders were sent to the spot. But when the firefighters and the police were unable to locate the source of the leak, a BSF disaster-response team was called in. Equipped with gas masks, the team entered the cold storage premises around $9.30 \mathrm{pm}$ and spotted broken valves and within an hour the valves and the cracked cylinder were repaired.

\section{Probable Causes of the Accident}

For the 1 st and 3rd incident

1. For 1 st incident - During charging of ammonia from the ammonia cylinder to the liquid line, the bottom valve $(1 / 2$ inch angle type) of the ammonia receiver ( $3 \mathrm{ft}$ O.D. and $12 \mathrm{ft}$ long) remained open. The pressure inside the receiver was around $15-18 \mathrm{~kg} / \mathrm{cm} 2$. As a result liquid ammonia came out from the receiver to the said liquid line due to backpressure, which ultimately released out developing the crack in the rubber hose. The rubber hose was designed to with stand up to $12 \mathrm{~kg} / \mathrm{cm} 2$.

2. No self-containing breathing apparatus was provided and maintained in the factory to tackle the circumstances arising out of such accidental leakage of ammonia as a result of which the time span of leakage of ammonia lengthened.

3. There was no provision of prevention measure like water sprinkler arrangement around the compressor room to avoid any dispersion of ammonia gas from the compressor room to the outside.

4. The compressor room was not provided with any windows. Only three exhaust fans at a height of about 15 ft., located at extreme west wall were provided and maintained which were not sufficient to ensure adequate ventilation in the room by circulation of fresh air.

5. The operator by mistake opened the valve attached to the ammonia receiver instead of opening the valve attached to the suction line of the ammonia compressor - clear indication of human error.

6. The workers are not properly trained to do the job.

For the 2nd incident

1. The main cause of the incident was corrosion in the bottom line of the oil drum.

2. Due to absence of preventive maintenance and presence of excessive moisture in the air the corrosion occurred.

3. Corrosion also occurred because of not carrying on periodic testing of those pipes, drains, and valves by any competent person.

4. All the pipelines and valves of the cold storage plant shall be periodically painted or made of stainless steel, to prevent corrosion effect.

E. Preventive Measure and Emergency Response Plan [2], [5]. [6]

According to EPA the prevention of accidental releases requires a holistic approach that integrates technologies, procedures, and management practices. The following basic element should consider preparing the emergency response plan

1. Process safety analysis

- Information of hazard, i.e., Material Safety Data Sheet

- Block diagram of the plant

- Complete piping system diagram (P \& I diagram)

- Details of relief valves - date of installation, size, capacity, date of inspection, maintenances etc.

- Alarm device - date of installation, inspection, maintenances etc.

- Equipment like pressure vessel, heat exchanger etc. with detail design with full knowledge of limiting operating conditions

2. Detail hazard analysis

- To identify the potential hazardous areas

- Check list

- On-site and Off-site consequences to be evaluated

3. Operation procedure (SOP)

- Startup procedure

- Normal procedure

- Shutdown procedure

- Normal procedure include all changes

- $\quad$ Limiting operating condition - upper limit and lower 
limit

- For outside limiting operating condition

- Emergency shutdown procedure

- Emergency procedure for any problem like leak etc.

- Lockout/tagout procedure

- Confined space entry under emergency

- Opening process equipment and piping

- Control of access to the plant - plant management controls the activities and safety of workers

- Proper ventilation in the workspace

1. Training - Each and every worker needs an appropriate training to operate plant safely. Establish training programs to ensure that the ammonia refrigeration system is operated and maintained by knowledgeable personnel. Training to be provided regular interval of time say once in two years.

2. As ammonia is highly soluble in water so water sprinkler arrangement should be provided in the entire plant.

3. Compliance Audits - management ensure that their employees properly carried out their duties to prevent any accident.

4. Accident Investigation - near miss event or accident must be properly investigated to prevent future occurrence.

5. Employee Participation in all aspects of the plant safety Prevention program about process safety workers should participate in process hazards analyses and be consulted as to how the other elements of the Prevention Program are carried out. If required then a written plan distributes to operators to follow safe work procedure.

6. Emergency response programme - for maintenance, fire, safety and environment, personnel, security and medical.

7. Provide emergency response system -

- Arrange internal alarm system to indicate any leakage of ammonia.

- Maintenance and periodical check-up of self-contained breathing apparatus.

- Self-contained breathing apparatus should be checked periodically.

- Develop proper communication system through telephone, internet etc. to inform any emergency onsite and off-site of the plant.

- Training off-site local people for emergency situation.

- Regular and periodical training for workers.

- Arrange mock drills for workers.

\section{CONCLUSION}

The accidental ammonia leakages from cold storage units have been reported. The causes of the accidents, the preventive measures and the necessary emergency response have been discussed.

\section{REFERENCES}

[1] Y. Henderson and H. W. Haggard, Noxious Gases, Reinhold, New York, 1943.

[2] R. K. Gangopadhyay and S. K. Das, Ammonia leakage from refrigeration plant and the management practice, Process Safety Progress, Vol. 27, and No. 1. Pp. 15-20, 2008.

[3] National Institute for Occupational Safety and Health, NIOSH Recommended Standard for Occupational Exposure to Ammonia, US Department of Health, Education, and Welfare, Rockville, MD, 1974.

[4] Newspaper Times of India, Kolkata edition, dt 24.01.2011.

[5] V. Reston and A. May Science Applications International Corporation (SAIC) Model risk management program and plan for ammonia refrigeration, 1996.

[6] United States Environmental Protection Agency, Report No. EPA-F-01$009 \quad$ August 2001 [http://Yosemite.epa.gov/oswer/CeppoWeb.nsf/vwResourcesByFilenam e/ammonia.pdf/\$File/ammonia.pdf] seen on dt. $27^{\text {th }}$ Oct. 2007.

[7] Toxicological profile for ammonia- U.S. department of health and human services, Public Health Service, Agency for Toxic Substances and Disease Registry, September, 2004.

[8] E.S. White, A case of near fatal ammonia gas poisoning. J. Occupational. Medicine, Vol.13, Pp. 543-550, 1971.

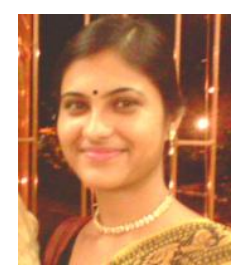

Ms. Gargi Bhattacharjee obtained her M. Sc. in Home Science with specialization in Human Development from University of Calcutta, 2008. She submitted her Ph. D. thesis, August 2012, in University of Calcutta. She published three research papers in International Journals.

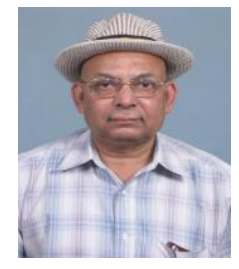

Mr.S. Bhattacharya obtained his B.Sc. (Hons.) in Chemistry, 1971, B.Tech. in Chemical Engineering, 1974 from University of Calcutta and M.Tech.in Chemical Engineering with specialization in Plant Design \& Fabrication, I.I.T. Kharagpur, 1978. He worked in different capacity in Petroleum and Explosives Safety Organization, Govt. of India, and retired as Joint Chief Controller of Explosives, Eastern Circle, Kolkata in 2011.

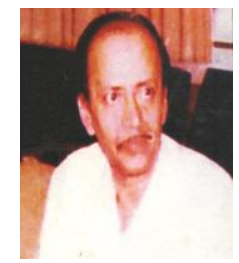

Dr. R. K. Gangopadhyay obtained his bachelor degree in Electrical Engineering, 1966 and LLB, 1977 from University of Calcutta and $\mathrm{Ph}$. D. from BIT, Mishra, 2006. He started is carrier as engineer in Indian Railways from 1966 - 1667, Andrew Yule Company Ltd. From 1967-1968, Department of Labour, Govt. of West Bengal, 1968-2003. He served the Department of Labour, Govt. of West Bengal as different capacities and retired as Chief Inspector of Factories, Govt. of West Bengal.

Dr.S.K. Das obtained B. Sc. (Hons.) in Chemistry, 1979, B. Tech. in (a) Chemical Engineering, 1982 from University of Calcutta, M. Tech. in Chemical Engineering from I.I.T., Kharagpur in 1984, and Ph. D. in Chemical Engineering from I.I.T., Kharagpur in 1988. Presently he is Associate Professor in the Department of Chemical Engineering, University of Calcutta. He is working in different fields like, multiphase flow, process safety, environmental engineering, CFD and ANN. He served as a Honorary Secretary in Indian Institute of Chemical Engineers, chaired number of International and National Seminars. He is associated as a reviewer for at least 30 International/National Journals. He has published 4 chapters in books, 110 papers in the International, National journals and International Conference Proceedings with proper ISSN/ISBN number. He has presented 12 invited lectures and 140 papers in the International/National Seminars. His papers have been cited about 600 times in various books and journals. 